\title{
anu \\ Compensation of Torque-Producing Stator Current Error for Vector-Controlled Induction Motor Drives
}

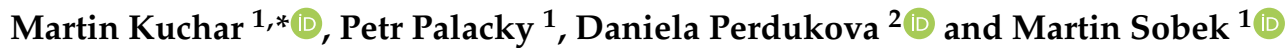 \\ 1 Department of Electronics, Faculty of Electrical Engineering and Computer Science, VSB-Technical \\ University of Ostrava, 70800 Ostrava, Czech Republic; petr.palacky@vsb.cz (P.P.); martin.sobek@vsb.cz (M.S.) \\ 2 Department of Electrical Engineering and Mechatronics, Faculty of Electrical Engineering and Informatics, \\ Technical University of Kosice, 04200 Kosice, Slovakia; daniela.perdukova@tuke.sk \\ * Correspondence: martin.kuchar@vsb.cz
}

check for updates

Citation: Kuchar, M.; Palacky, P.; Perdukova, D.; Sobek, M Compensation of Torque-Producing Stator Current Error for VectorControlled Induction Motor Drives. Energies 2022, 15, 815. https:// doi.org/10.3390/en15030815

Academic Editor: Abu-Siada Ahmed

Received: 19 December 2021

Accepted: 19 January 2022

Published: 23 January 2022

Publisher's Note: MDPI stays neutral with regard to jurisdictional claims in published maps and institutional affiliations.

Copyright: (C) 2022 by the authors. Licensee MDPI, Basel, Switzerland. This article is an open access article distributed under the terms and conditions of the Creative Commons Attribution (CC BY) license (https:/ / creativecommons.org/licenses/by/ $4.0 /)$.

\begin{abstract}
This paper presents a detailed analysis of dynamic properties and accuracy issues of the torque-producing stator current control loop for vector-controlled induction motor drives. In this paper, a necessary mathematical description of vector control of an induction motor is shown with respect to the $x$-axis and $y$-axis current control in the rotating reference frame. A derivation of a steady-state error for the torque-producing stator current control scheme with and without a decoupling algorithm is described. The presented derivation and dynamic behavior of both these schemes were extensively tested in the MATLAB-SIMULINK software, considering different values for the moment of inertia. This solution was implemented in a DSC-based induction motor drive using a voltage source inverter to obtain experimental results. Moreover, the advantages of using the presented decoupling block for compensation of the problem are discussed at the end of the paper.
\end{abstract}

Keywords: induction motor; steady-state current error; torque current component; variable speed drive; vector control

\section{Introduction}

Electrical drives, the main objective of which is a system utilization of electrical machines for electromechanical energy conversion and for control of this transformation, comprise a very important sector of electrical engineering.

At present, variable speed electrical drives with induction motors belong to an industry standard. These drives use two basic techniques to control the magnetic flux and torque: vector control and direct torque control [1-5].

For supplying of induction motors, frequency converters with different types of structures and control methods are used [6,7].

In general, it is well known that a current control loop of DC or AC drives operates with a steady-state error during the rotor speed transient states, even when proportional integral (PI) current controllers are used [8]. This error is a problematic issue, especially for fast torque (current) control or time-optimal position control methods, because in these cases, the real motor torque is less than a reference value (steady-state error). This topic is important in the field of traction applications or robotics. In these cases, it is necessary to find methods to suppress the current control error.

Sensorless drives, sensor fault tolerant control and applications of artificial intelligence belong to the top topics in the field of sophisticated control methods for electrical controlled drives. In these cases, the vector control algorithm is mostly used as a basic control method [9-15]. This is the reason why it is important to suppress the aforementioned current control steady-state error, to reach the best possible performance of the drive. Equations for the elimination of the coupling between the flux- and torque-producing stator current components are very often used for vector-controlled induction motor drives. The aforementioned coupling occurs in the voltage equations expressed in the rotating 
reference frame $[x, y]$ oriented on the rotor flux space vector. It is well known from the literature [16-20] that the decoupling equations are important for independent control of the stator current space vector components. Moreover, the coupling can deteriorate the current responses in the high-speed range if it is not well compensated [20].

A comparative study of two decoupling control methods, based on the theory of differential geometry and the conventional vector control, is shown in [21]. In this case, the decoupling between the flux linkage subsystem and the rotor speed subsystem is investigated in different drive operations. A new state equation of an induction motor is proposed in [22] for easy design of the decoupling system. A robust decoupling current controller is presented in [18] and is based on an internal model control method. In [17], a similar decoupling controller was investigated with the goal to be more robust to the parameter variation. Two additional PI controllers in the coupling paths are used in $[19,20]$. If an output voltage vector of the current controllers is greater than the maximum inverter voltage, it is decreased by a reducing technique called overmodulation. In [20], the overmodulation technique is improved for better torque transient response. All mentioned references are focused on the important issues of the coupling, but this paper deals with the problems concerning the steady-state error of the torque-producing stator current control during the rotor speed changes. The proposed decoupling equations eliminate the steady-state current error. In the paper, a detailed and comprehensive analysis of the problem is presented, including a mathematical description of how the current error can be calculated.

This paper is organized as follows. Sections 2 and 3 deal with the mathematical model of a vector-controlled induction motor and used control structure. Section 4 focuses on the analysis and compensation of the current control error. Simulation and experimental results are shown in Sections 5 and 6, respectively. Finally, conclusions are presented in Section 7.

\section{Mathematical Model of Vector-Controlled Induction Motor}

The vector control of an induction motor is based on the separation of the stator current space vector into two perpendicular components, flux producing $i_{S x}$ and torque producing $i_{S y}$. The components define the magnetization and torque of an induction motor [4].

The $x$-axis of the $[x, y]$ rotating reference frame is determined by the position of the rotor flux space vector $\Psi_{R}$ or magnetizing current space vector $\mathbf{i}_{m}$, respectively, (see Figure 1).

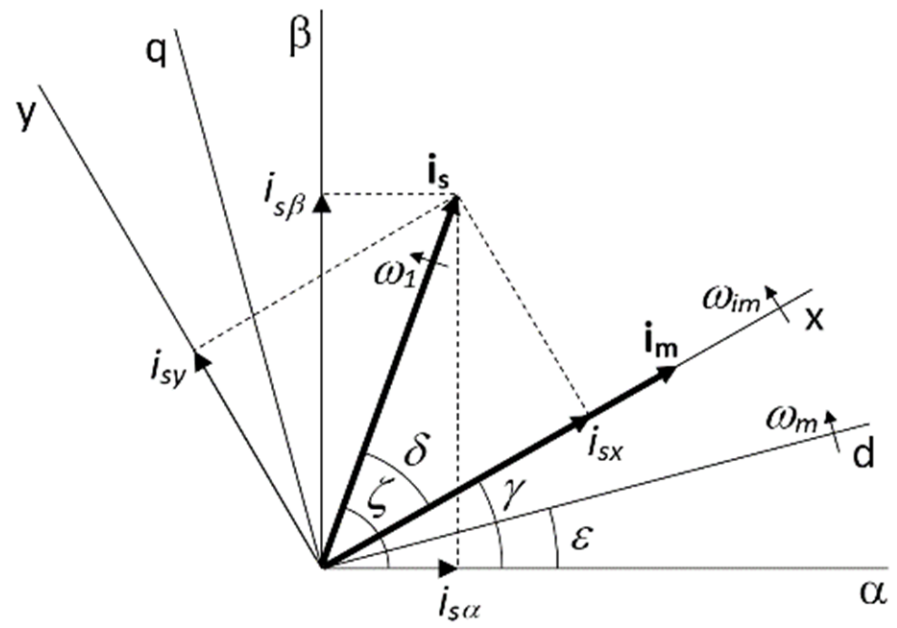

Figure 1. Components of stator current space vector.

The induction motor model can be described in the different complex reference frames (see Figure 1). 
The following voltage equations can be derived for the components of the stator voltage space vector expressed in the $[x, y]$ rotating reference frame:

$$
\begin{aligned}
& u_{S x}=R_{S} i_{S x}+\sigma L_{S} \frac{d i_{S x}}{d t}-\omega_{i m} \sigma L_{S} i_{S y}+(1-\sigma) L_{S} \frac{d i_{m}}{d t}, \\
& u_{S y}=R_{S} i_{S y}+\sigma L_{S} \frac{d i_{S y}}{d t}+\omega_{i m}\left[\sigma L_{S} i_{S x}+(1-\sigma) L_{S} i_{m}\right] .
\end{aligned}
$$

The following equations can be defined for the induction motor torque and other variables corresponding to Figure 1:

$$
\begin{gathered}
t_{E}=\frac{3}{2} p \frac{L_{h}}{L_{R}} \Psi_{R} i_{S y}=\frac{3}{2} p \frac{L_{h}^{2}}{L_{R}} i_{m} i_{S y}, \\
t_{E}-t_{L}=J_{t} \frac{d \Omega_{m}}{d t}, \\
p \Omega_{m}=\frac{d \varepsilon}{d t}, \\
i_{m}+T_{R} \frac{d i_{m}}{d t}=i_{S x}, \\
\omega_{2}=\omega_{1}-\omega_{m}=\omega_{1}-p \Omega_{m}=\frac{i_{S y}}{i_{m} T_{R}}, \\
\omega_{1}=\omega_{i m}+\frac{d \delta}{d t}=\frac{d \xi}{d t}, \\
\omega_{i m}=\frac{d \gamma}{d t}, \\
\xi=\gamma+\delta, \\
T_{S}=\frac{L_{S}}{R_{S}}, \\
T_{R}=\frac{L_{R}}{R_{R}}, \\
\Psi_{R}=L_{h} i_{m} .
\end{gathered}
$$

It is possible to obtain the following equations for the stator current components from the voltage Equations (1) and (2). After the Laplace transformation and by neglecting changes of the magnetizing current, the relations for the stator current space vector components in the $x$-axis and $y$-axis can be defined as:

$$
\begin{gathered}
i_{S x}=\frac{1}{R_{S}} \frac{1}{\left(1+s \sigma T_{S}\right)}\left[u_{S x}+\omega_{i m} \sigma L_{S} i_{S y}\right], \\
i_{S y}=\frac{1}{R_{S}} \frac{1}{\left(1+s \sigma T_{S}\right)}\left[u_{S y}-\omega_{i m}\left(\sigma L_{S} i_{S x}+(1-\sigma) L_{S} i_{m}\right)\right] .
\end{gathered}
$$

Members in square brackets in (14) and (15), respectively, represent undesirable coupling between the $x$ and $y$ components.

The stator current control scheme of the vector-controlled induction motor drive without decoupling block (see Figure 2) can be drawn on the basis of Equations (14) and (15).

Figure 2 shows the obvious coupling between the flux current component $i_{S x}$ and the torque current component $i_{S y}$ according to Equations (14) and (15).

The control scheme shows the current control of both current components without decoupling. Sections 4-6 deal with the torque-producing stator current control only, i.e., 
the influence of the flux-producing stator current $i_{S x}$ to the torque-producing stator current $i_{\text {Sy }}$ only.

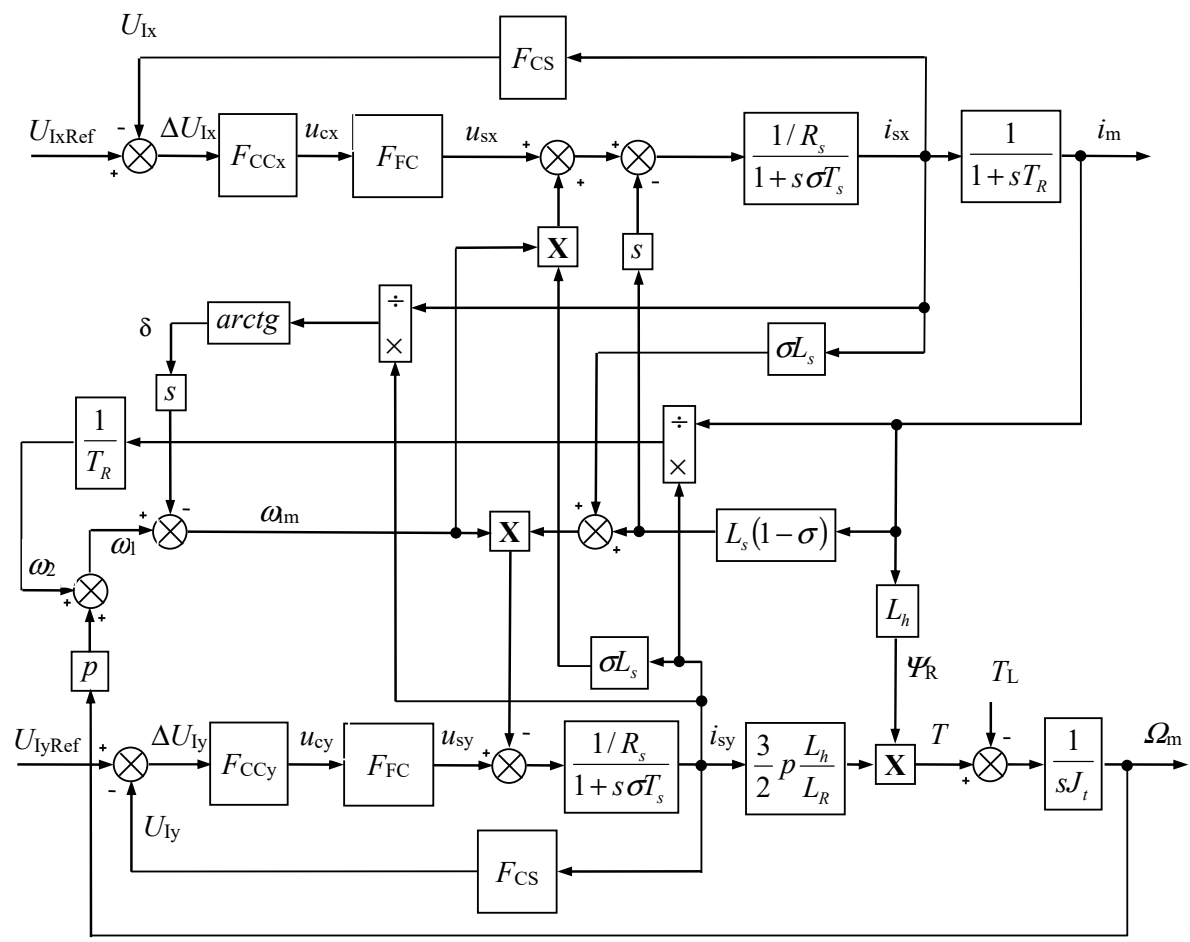

Figure 2. Stator current control scheme of vector-controlled induction motor without decoupling block.

To cancel the coupling between the current space vector components, a decoupling block is used. It can be implemented as members that are added to the outputs of the current controllers in the individual axes using the following equations:

$$
\begin{gathered}
u_{k x}=-\omega_{i m} \sigma L_{S} i_{S y} \\
u_{k y}=\omega_{i m}\left[\sigma L_{S} i_{S x}+(1-\sigma) L_{S} i_{m}\right] .
\end{gathered}
$$

For the analysis of the decoupling influence in Sections 4-6, the steady-state in terms of excitation is considered $\left(i_{m}=i_{S x}\right)$. In this case, it is possible to derive the following Equations (18) and (19) using Equations (15) and (17):

$$
\begin{gathered}
i_{S y}=\frac{1}{R_{S}} \frac{1}{\left(1+s \sigma T_{S}\right)}\left[u_{S y}-\omega_{i m} L_{S} i_{m}\right], \\
u_{k y}=\omega_{i m} L_{S} i_{m} .
\end{gathered}
$$

\section{Control Structure of Induction Motor Drive}

The control structure of the vector-controlled induction motor drive is shown in Figure 3. The control structure uses the space vectors expressed in the rotating reference frame oriented on the rotor magnetic flux. The current control loops are designed as subordinate loops of the speed and flux (magnetizing current) control.

The estimation of the magnetizing current $i_{m}$ and orienting quantities $\sin \gamma$ and $\cos \gamma$ is carried out using the so-called current model of an induction motor (see block Motor model in Figure 3). This model uses the rotor angle $\varepsilon$ and the rotor time constant $T_{R}$ for the estimation of the stator current space vector components in the $[\alpha, \beta]$ stationary reference frame. 


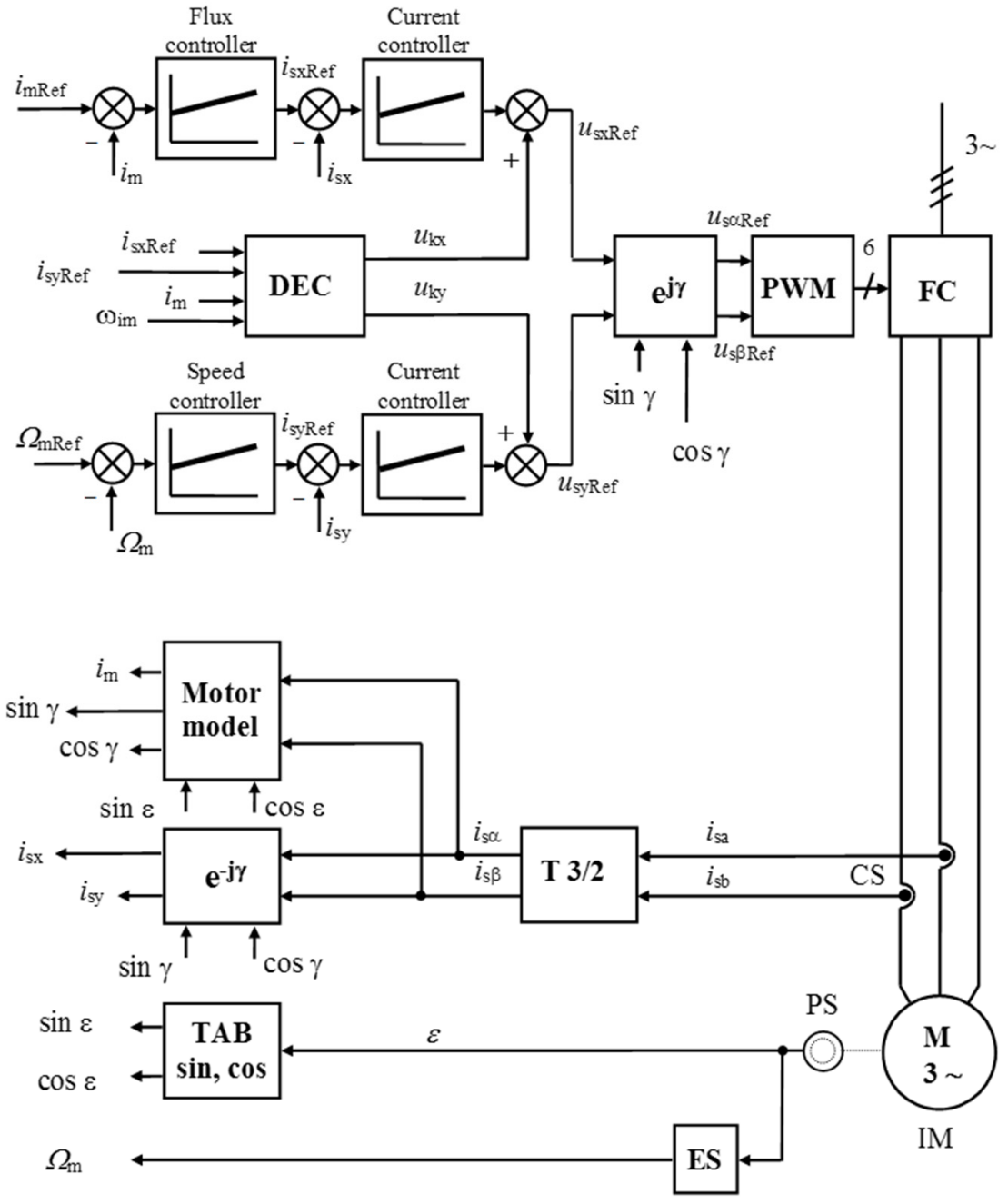

Figure 3. Vector-controlled induction motor drive.

The orienting angle $\gamma$ is used for the Park transformation of the complex space vector components from the $[\alpha, \beta]$ stationary reference frame to the $[x, y]$ rotating reference frame (see block $\mathrm{e}^{-j \gamma}$ in Figure 3) and for the reverse transformation (see block $\mathrm{e}^{\mathrm{j} \gamma}$ in Figure 3).

The reference flux-producing stator current $i_{S x \text { Ref }}$ is determined by the PI controller of the magnetizing current, which processes control error between the reference value $i_{m R e f}$ and actual value of the magnetizing current $i_{m}$. The magnetizing current is estimated in the block Motor model (see Figure 3).

The reference magnetizing current $i_{m R e f}$ is constant (nominal) in the operating range from $0 \mathrm{rpm}$ to the nominal speed $\Omega_{m N}$. The reference magnetizing current $i_{m R e f}$ decreases for the higher speeds (field weakening mode) according to the following relation:

$$
i_{m R \mathrm{e} f}=i_{m N} \frac{\Omega_{m N}}{\Omega_{m}} .
$$

In Figure 3, there is the following description of the blocks:

FC - Frequency Converter; CS —Current Sensor; PWM-Pulse Width Modulation; PSPosition Sensor; ES-Evaluation of Speed; IM-Induction Motor; DEC—Decoupling block.

The reference torque-producing stator current $i_{\text {SyRef }}$ is determined by the PI speed controller.

Both components of the stator current space vector are then controlled in the subordinate current control loops. The voltage components $u_{k x}$ and $u_{k y}$ are evaluated in the 
decoupling block DEC according to Equations (16) and (17). They are added to the outputs of the current controllers to suppress the coupling between the $x$-axis and $y$-axis.

\section{Steady-State Error of Torque-Producing Stator Current Control}

For the steady-state error analysis of the torque-producing stator current control, an induction motor drive in a laboratory of the Department of Electronics, VSB-Technical University of Ostrava is considered. The induction motor parameters (type P 112 M04) are shown in Table 1.

Table 1. Induction motor parameters.

\begin{tabular}{cc}
\hline Parameter & Value \\
\hline Rated power & $2.7 \mathrm{~kW}$ \\
Rated torque & $19 \mathrm{Nm}$ \\
Rated speed & $1360 \mathrm{rpm}$ \\
Rated stator voltage & $400 / 230 \mathrm{~V}$ \\
Rated stator current & $7.51 \mathrm{~A}$ \\
Rated stator magnetic flux & $0.877 \mathrm{~Wb}$ \\
Number of pole pairs & 2 \\
Stator resistance & $2.10 \Omega$ \\
Rotor resistance & $2.51 \Omega$ \\
Stator inductance & $0.137 \mathrm{H}$ \\
Rotor inductance & $0.137 \mathrm{H}$ \\
Rotor time constant & $54.6 \mathrm{~ms}$ \\
Moment of inertia & $0.013 \mathrm{kgm}^{2}$ \\
\hline
\end{tabular}

The induction motor is coupled mechanically with a DC machine (type MB $112 \mathrm{~S}-\mathrm{T}$ ) that has the following parameters: $P_{N}=1.5 \mathrm{~kW}, J_{D C M}=0.022 \mathrm{kgm}^{2}$. The total moment of inertia including mechanical coupling is $J_{t}=0.043 \mathrm{kgm}^{2}$.

The induction motor is powered by a frequency converter with a voltage source inverter. The DC link voltage $U_{d}=540 \mathrm{~V}$.

The control of the frequency converter output voltage is based on the sinusoidal pulse-width modulation using a sawtooth voltage with frequency $f_{p}=2 \mathrm{kHz}$ and amplitude $U_{\text {pmax }}= \pm 10 \mathrm{~V}$.

The frequency converter gain is defined as $K_{F C}=(1 / 2) \cdot U_{d} / U_{p \max }=(1 / 2) \cdot 540 / 10=27$ and the frequency converter time constant is defined as $T_{F C}=1 /\left(2 \cdot f_{p}\right)=1 /(2 \cdot 2000)=$ $0.00025 \mathrm{~s}=0.25 \mathrm{~ms}$. The frequency converter transfer function called $F_{F C}$ is treated as a first-order transfer function.

The torque-producing stator current control structure can be created using the following transfer functions:

$F_{C S}$ - current sensor transfer function, current sensor gain $K_{C S}=1 \mathrm{~V} / \mathrm{A}$, time constant $T_{C S}=0.5 \mathrm{~ms} . F_{C S}$ is treated as a first-order transfer function.

$F_{\mathrm{CC} y}$-torque-producing stator current controller transfer function, current controller gain $K_{C C y}=0.4$, time constant $T_{C C y}=8 \mathrm{~ms}$.

$F_{\mathrm{SS}}$ - speed sensor transfer function. An incremental sensor IRC 120/1024 is used to measure the rotor speed and position with the four times multiplication of the output pulses. In this case, the number of pulses per one revolution is 4096. The used sampling period for speed evaluation is $T_{\mathrm{V}}=5 \mathrm{~ms}$, so the speed sensor time constant is $T_{\mathrm{SS}}=T_{\mathrm{V}} / 2=2.5 \mathrm{~ms}$. The speed sensor gain $K_{\mathrm{SS}}$ is assumed to be equal to 1 .

For the analysis, the nominal excitation of the induction motor in steady-state is considered (magnetizing current $I_{m}=6 \mathrm{~A}$ ). This corresponds to the condition $i_{m}=i_{S x}$ and the validity of Equations (18) and (19). The influence of the load torque $T_{L}$, slip angular frequency $\Omega_{2}$ and time derivative of the load angle $\delta$ are neglected. 
4.1. Torque-Producing Stator Current Control Structure without Decoupling Block

The torque-producing stator current control structures without the decoupling block are shown in Figures 4 and 5.

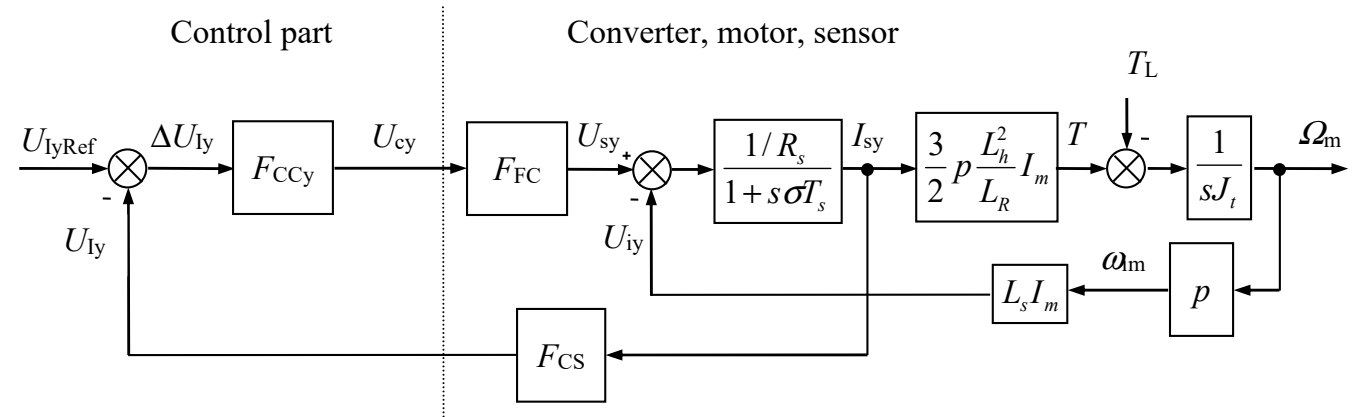

Figure 4. Torque-producing stator current control structure without decoupling block.

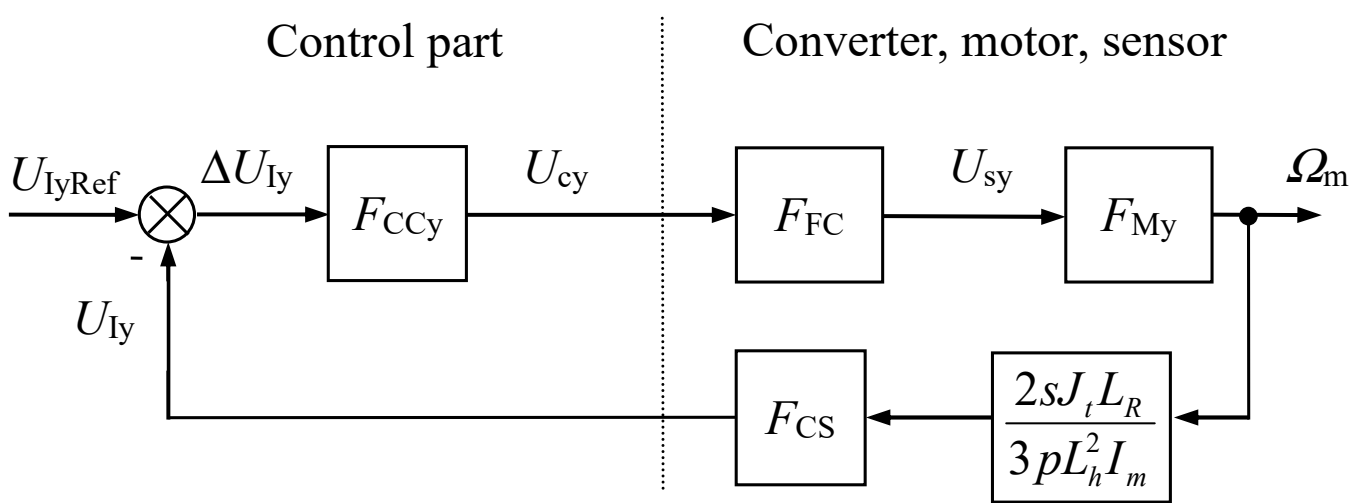

Figure 5. Adjusted torque-producing stator current control structure without decoupling block.

The transfer function $F_{M y}$ represents the induction motor transfer function in the y-axis:

$$
F_{M y}=\frac{\Omega_{m}}{U_{S y}}=\frac{1 /\left(p L_{S} I_{m}\right)}{\left(1+s T_{m}+s^{2} T_{m} \sigma T_{S}\right)}
$$

The term $T_{m}$ in the transfer function $F_{M y}$ can be regarded as the mechanical time constant. It is calculated for the total moment of inertia $J_{t}=0.043 \mathrm{kgm}^{2}$, using the motor parameters (see Table 1), by the following equation:

$$
\begin{aligned}
& T_{m}=\frac{2 J_{t} R_{S} L_{R}}{3 p^{2} L_{h}^{2} L_{S} I_{m}^{2}}= \\
& =\frac{2 \cdot 0.043 \cdot 2.1 \cdot 0.137}{3 \cdot 2^{2} \cdot 0.129^{2} \cdot 0.137 \cdot 6^{2}}=0.0251 \mathrm{~s}
\end{aligned}
$$

The term $\sigma T_{S}$ in the transfer function $F_{M y}$ can be regarded as the electromagnetic time constant:

$$
\begin{aligned}
& \sigma T_{S}=\left(1-\frac{L_{h}^{2}}{L_{S} L_{R}}\right) \frac{L_{S}}{R_{S}}= \\
& =\left(1-\frac{0.129^{2}}{0.137 \cdot 0.137}\right) \frac{0.137}{2.1}=0.00802 \mathrm{~s}
\end{aligned}
$$


From Figure 5, the transfer function of the open control loop for the torque-producing stator current is defined by the following equation:

$$
\begin{aligned}
& F_{0}=\frac{U_{I y}}{U_{I y R e f}-U_{I y}}=F_{C C y} F_{F C} F_{M y} \frac{s J_{t} L_{R}}{(3 / 2) p L_{h}^{2} I_{m}} F_{C S}= \\
& =K_{C C y} \frac{\left(1+s T_{C C y}\right)}{s T_{C Y}} \frac{K_{F C}}{\left(1+s T_{F C}\right)} \frac{1 /\left(p L_{s} I_{m}\right)}{\left(1+s T_{m}+s^{2} T_{m} s T_{S}\right)} \\
& \cdot \frac{s J_{t} L_{R}}{(3 / 2) p L_{h}^{2} I_{m}} \frac{K_{C S}}{\left(1+s T_{C S}\right)}= \\
& =K_{0} \frac{\left(1+s T_{C C y}\right)}{\left(1+s T_{F C}\right)\left(1+s T_{m}+s^{2} T_{m} s T_{s}\right)\left(1+s T_{C S}\right)}
\end{aligned}
$$

where the open loop gain $K_{0}$ is calculated by:

$$
\begin{aligned}
& K_{0}=\frac{K_{C C_{y} K_{F C} J_{t} L_{R} K_{C S}}}{T_{C C_{y}}(3 / 2) p^{2} L_{h}^{2} I_{S} I_{m}^{2}}= \\
& =\frac{0.4 \cdot 27 \cdot 0.043 .0 .137 .1}{0.008 \cdot(3 / 2) \cdot 2^{2} \cdot 0.129^{2} \cdot 0.137 \cdot 6^{2}}=16.15
\end{aligned}
$$

The steady-state current control error can be calculated according to the following equation:

$$
\begin{aligned}
& \Delta U_{\text {Iy }}=\lim _{s \rightarrow 0}\left(s \frac{1}{\left(1+F_{0}\right)} \frac{U_{\text {IyRef }}}{s}\right)= \\
& =\frac{1}{1+K_{0}} U_{\text {IyRef }}=\frac{1}{1+16.15} U_{\text {IyRef }}=0.0583 U_{\text {IyRef }}
\end{aligned}
$$

which represents the steady-state current control error $5.83 \%$ of the reference torqueproducing stator current for the considered parameters, although the PI controller is used. The main reason for the error is the back electromotive force (EMF) changes caused by the rotor speed transient-states (see Figures 4 and 5, respectively). Finally, this is the disadvantage of the torque-producing stator current control structure without the decoupling block. The first one is the well-known coupling between the current space vector components (see Section 3). The current control error increases with the lower moment of inertia (see Equation (26)).

\subsection{Torque-Producing Stator Current Control Structure with Decoupling Block}

The torque-producing stator current control structures with decoupling block are shown in Figures 6 and 7.

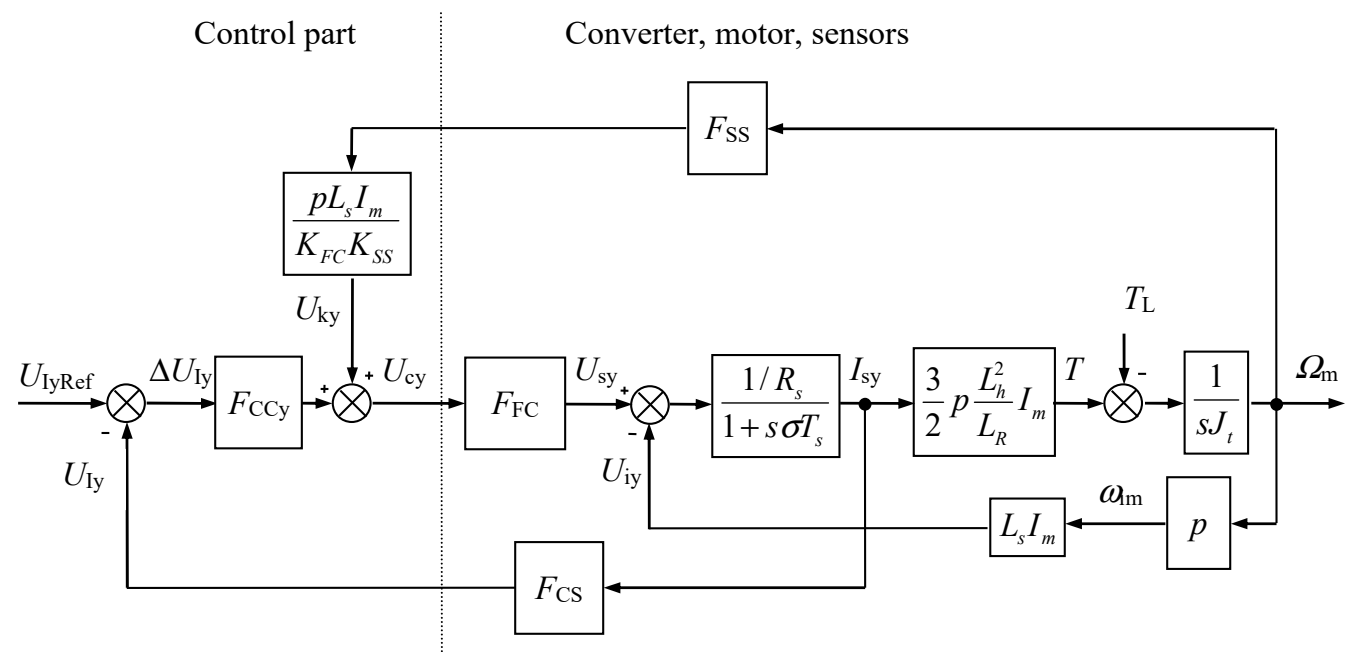

Figure 6. Torque-producing stator current control structure with decoupling block. 


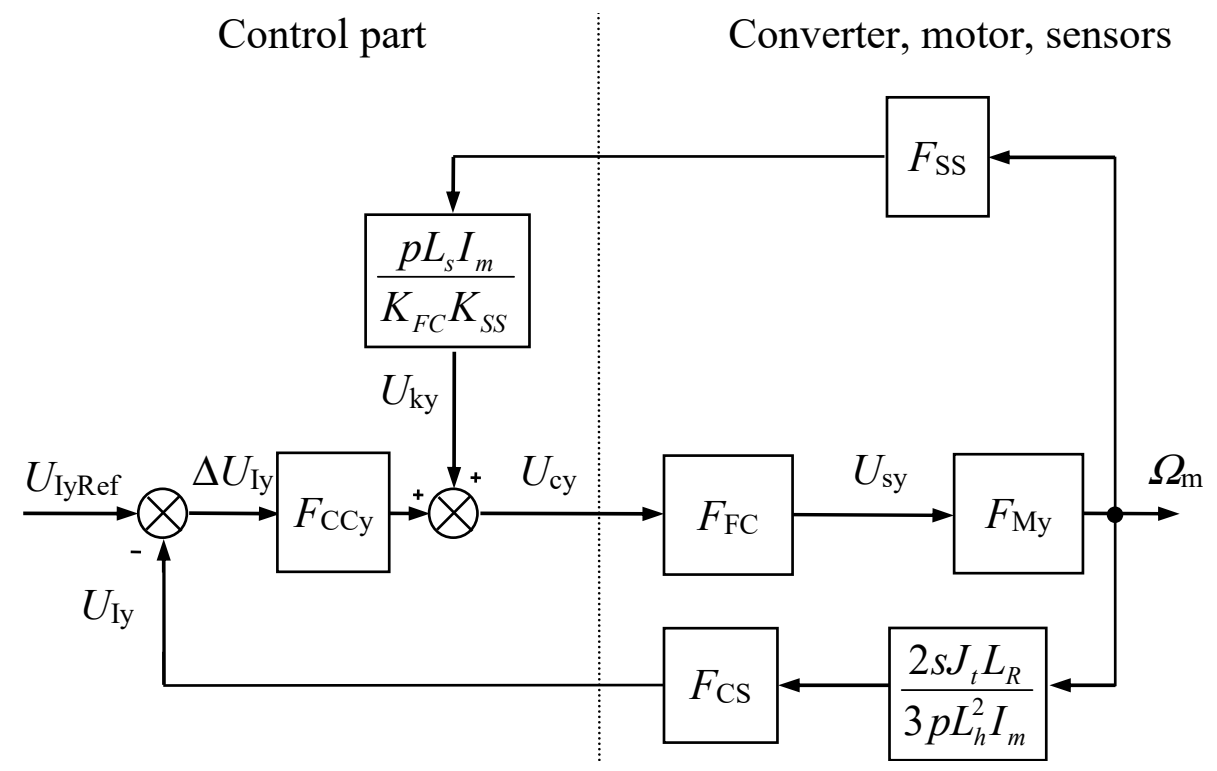

Figure 7. Adjusted torque-producing stator current control structure with decoupling block.

From Figures 6 and 7, the transfer function of the open control loop with the decoupling block is defined by the following equation:

$$
\begin{aligned}
& F_{0}=\frac{U_{I y}}{\Delta U_{I y}}=\frac{U_{I y}}{U_{I y R e f}-U_{I y}}= \\
& =F_{C C y} \frac{F_{F C} F_{M y}}{\left(1-\frac{F_{F C} F_{M y} F_{S S} p L_{S} I_{m}}{K_{S S} K_{F C}}\right)} \frac{s J_{t} L_{R}}{(3 / 2) p L_{h}^{2} I_{m}} F_{C S}= \\
& =K_{C C y} \frac{\left(1+s T_{C C y}\right)}{s T_{C C y}} \cdot \\
& \cdot \frac{\frac{K_{F C}}{\left(1+s T_{F C}\right)} \frac{1 /\left(p L_{S} I_{m}\right)}{\left(1+s T_{m}+s^{2} T_{m} \sigma T_{S}\right)}}{\left(1-\frac{K_{F C}}{\left(1+s T_{F C}\right)} \frac{1 /\left(p L_{S} I_{m}\right)}{\left(1+s T_{m}+s^{2} T_{m} \sigma T_{S}\right)} \frac{K_{S S}}{\left(1+s T_{S S}\right)} \frac{p L_{S} I_{m}}{K_{S S} K_{F C}}\right)} \cdot \\
& \cdot \frac{s J_{t} L_{R}}{(3 / 2) p L_{h}^{2} I_{m}} \frac{K_{C S}}{\left(1+s T_{C S}\right)}
\end{aligned}
$$

The steady-state current control error is defined as follows:

$$
\Delta U_{\text {Iy } \infty}=\lim _{s \rightarrow 0}\left(s \frac{1}{\left(1+F_{0}\right)} \frac{U_{\text {IyRef }}}{s}\right)=0
$$

In this case, it is evident that the steady-state current error is zero during the rotor speed transient-states.

\section{Simulation Results}

Models of the presented stator current control structures (Figures 4 and 6) were created in the simulation software MATLAB-Simulink.

The actual and reference torque-producing stator currents $i_{S y}$ and $i_{S y R e f}$ obtained from the control structure without the decoupling block are presented in Figure 8a,b and with the decoupling block in Figure 9a,b. The simulation results confirm the derived steadystate current control errors mentioned in Section 4 for the situation of the rotor speed transient-states (acceleration of the drive).

In the case of the control structure with the decoupling block, the steady-state error is equal to zero (see Figure 9a,b) which corresponds to (28). 


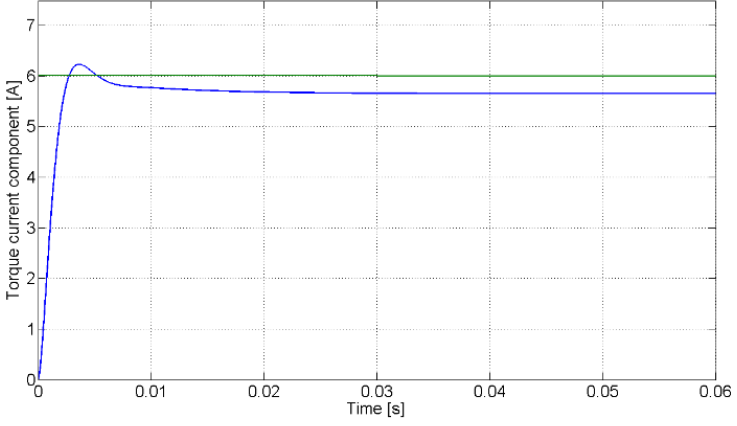

(a)

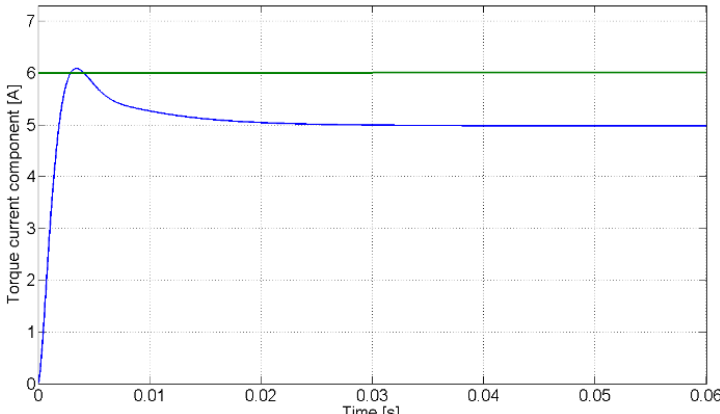

(b)

Figure 8. Simulation results: reference (green) and actual (blue) torque-producing stator current without decoupling; (a) total moment of inertia $J_{t}=0.043 \mathrm{kgm}^{2}$ (including DC machine), steady-state value of torque-producing stator current is $5.65 \mathrm{~A}$; (b) total moment of inertia $J_{t}=J_{M}=0.013 \mathrm{kgm}^{2}$ (induction motor only), steady-state value of torque-producing stator current is $4.98 \mathrm{~A}$.

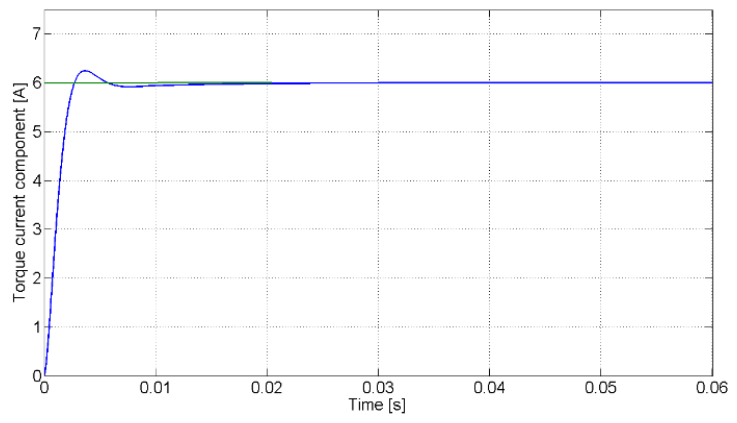

(a)

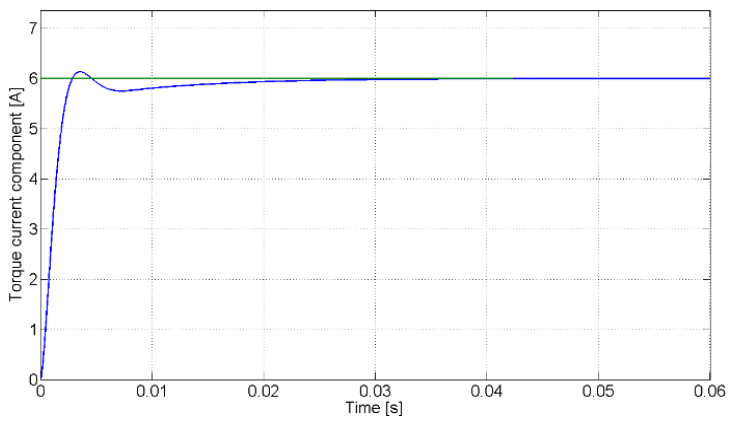

(b)

Figure 9. Simulation results: reference (green) and actual (blue) torque-producing stator current with decoupling; (a) total moment of inertia $J_{t}=0.043 \mathrm{kgm}^{2}$ (including DC machine), steady-state value of torque-producing stator current is $6 \mathrm{~A}$; (b) total moment of inertia $J_{t}=J_{M}=0.013 \mathrm{kgm}^{2}$ (induction motor only), steady-state value of torque-producing stator current is $6 \mathrm{~A}$.

In the control structure without the decoupling block, the steady-state error for the total moment of inertia $J_{\mathrm{t}}=0.043 \mathrm{kgm}^{2}$ is equal to $100 \cdot(6-5.65) / 6=5.83 \%$ (see Figure $8 \mathrm{a}$ ), which numerically corresponds to the result in accordance with (26). The steady-state error for the total moment of inertia $J_{\mathrm{t}}=J_{\mathrm{m}}=0.013 \mathrm{kgm}^{2}$ is equal to $100 \cdot(6-4.98) / 6=17 \%$ (see Figure $8 b$ ), which also numerically corresponds to the result in accordance with (29). For this reduced moment of inertia, it is possible to calculate (according to (25)) the open loop gain $K_{0}=4.88$ against to the original value $K_{0}=16.15$. In this case, the steady-state current control error is defined by the following Equation (29) using Equation (26):

$$
\begin{aligned}
& \Delta U_{\text {Iy }}=\frac{1}{1+K_{0}} U_{\text {IyRef }}= \\
& =\frac{1}{1+4.88} U_{\text {IyRef }}=0.170 U_{\text {IyRef }}
\end{aligned}
$$

In Figure 10a,b, the actual rotor speeds are shown for acceleration of the AC drive with the torque-producing stator currents according to Figures 8 and 9. It is evident that the vector-controlled AC drive with the decoupling block provides better dynamic performance. 


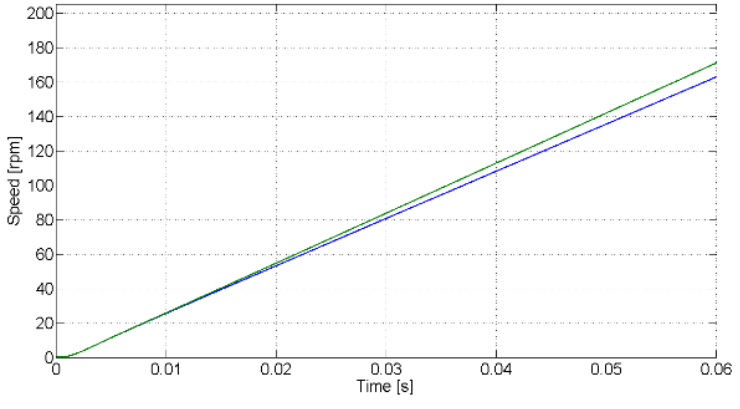

(a)

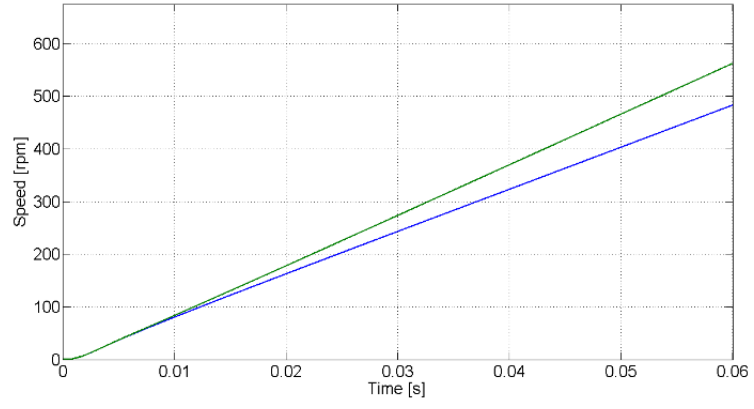

(b)

Figure 10. Simulation results: (a) actual rotor speed for torque-producing stator current without decoupling according to Figure 8a (blue) and with decoupling according to Figure 9a (green), total moment of inertia $J_{t}=0.043 \mathrm{kgm}^{2}$ (including DC machine); (b) actual rotor speed for torque-producing stator current without decoupling according to Figure $8 \mathrm{~b}$ (blue) and with decoupling according to Figure $9 \mathrm{~b}$ (green), total moment of inertia $J_{t}=0.013 \mathrm{kgm}^{2}$ (induction motor only).

\section{Experimental Results}

The presented control structures are experimentally tested on a laboratory stand to verify the theoretical assumptions and the simulation results of the steady-state torqueproducing stator current error during acceleration or deceleration of the drive. The laboratory stand consists of the induction motor fed by a voltage source inverter and a Texas Instruments Digital Signal Controller TMS320F28335 based control system.

The same induction motor parameters are used in the simulation stage and the experimental testing (see Table 1). The vector control method, including the decoupling algorithm, is implemented in the DSC control system with the sampling frequency of $50 \mu \mathrm{s}$.

Figure 11a,b shows the experimental results during the acceleration of the IM drive from 0 to $500 \mathrm{rpm}$ and reversal to $-500 \mathrm{rpm}$ without the decoupling block (Figure 11a) and with the decoupling algorithm (Figure 11b). The IM drive is not subjected to load.

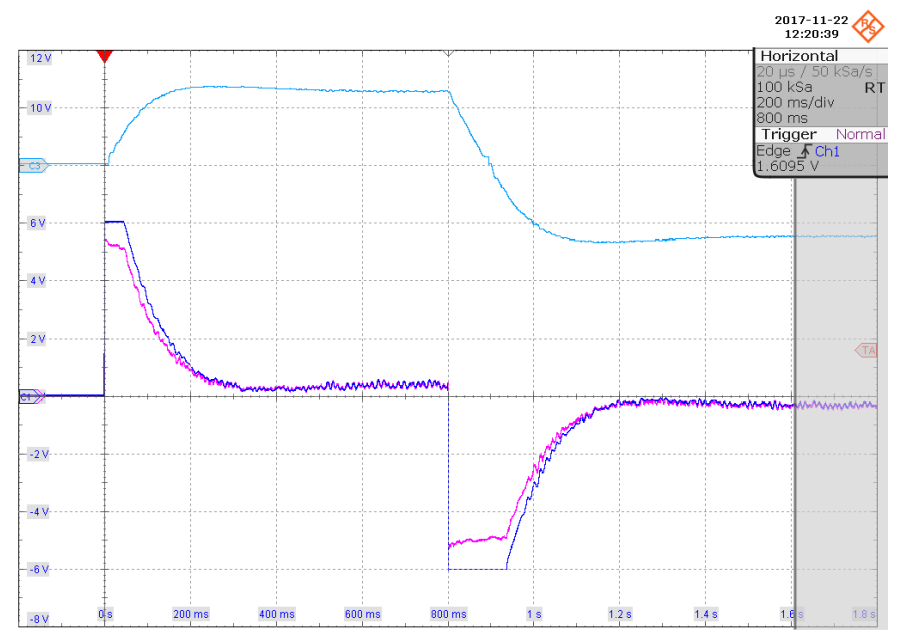

(a)

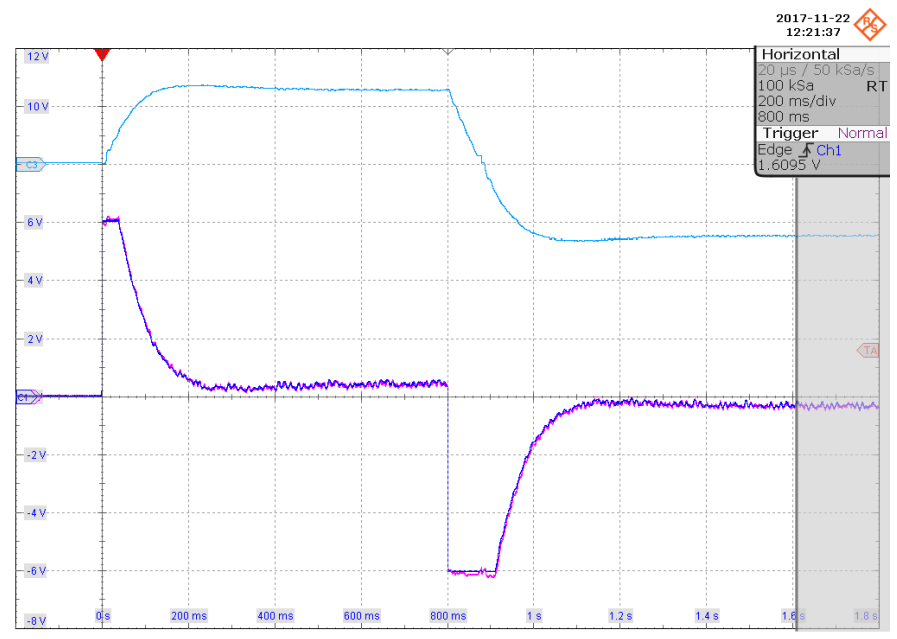

(b)

Figure 11. Experimental results: acceleration from 0 to $500 \mathrm{rpm}$ and reversal, actual rotor speed (light blue), the reference (dark blue) and actual (pink) torque-producing stator current, total moment of inertia of $J_{t}=J_{M}=0.013 \mathrm{kgm}^{2}$ (induction motor only), current scale $2 \mathrm{~A} / \mathrm{div}$, speed scale $400 \mathrm{rpm} / \mathrm{div}$, time scale $200 \mathrm{~ms} / \mathrm{div}$; (a) without decoupling; (b) with decoupling. 
Figure 12a,b shows the experimental results in detail during the acceleration of the IM drive from 0 to 500 rpm without the decoupling block (Figure 12a) and with the decoupling algorithm (Figure 12b).

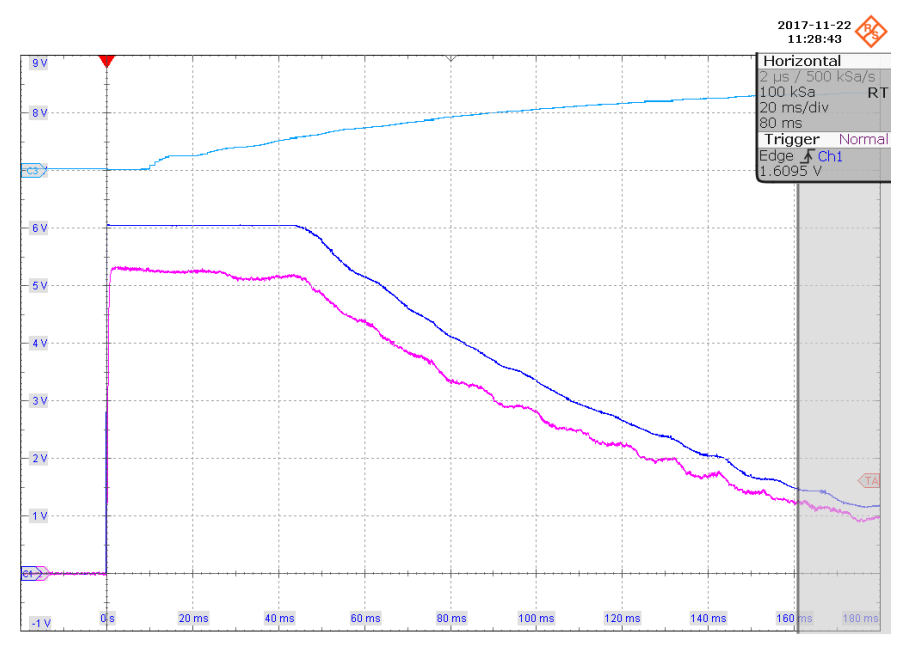

(a)

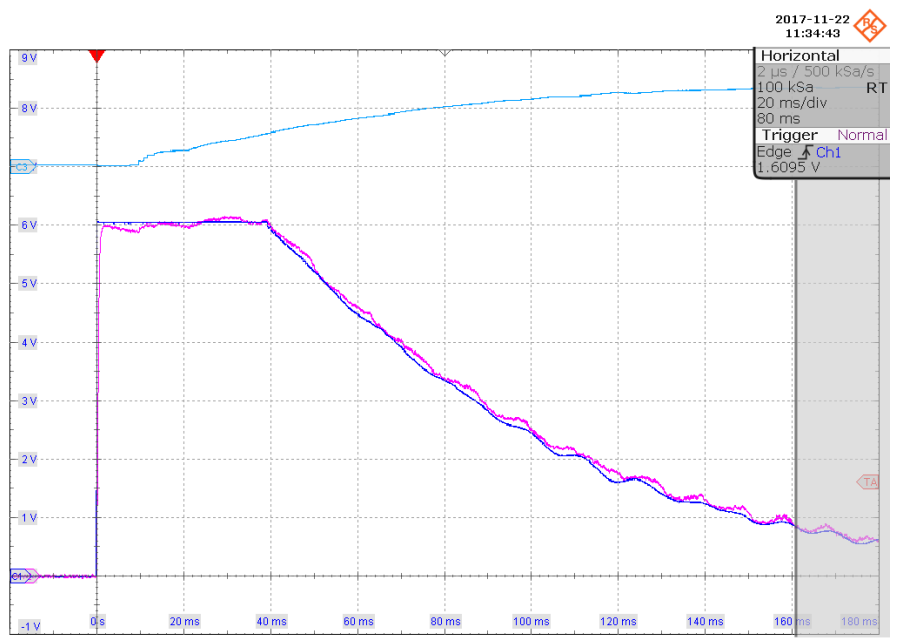

(b)

Figure 12. Experimental results: detail of acceleration from 0 to $500 \mathrm{rpm}$, actual rotor speed (light blue), the reference (dark blue) and actual (pink) torque-producing stator current, total moment of inertia of $J_{t}=J_{M}=0.013 \mathrm{kgm}^{2}$ (induction motor only), current scale $1 \mathrm{~A} / \mathrm{div}$, speed scale $400 \mathrm{rpm} / \mathrm{div}$, time scale $20 \mathrm{~ms} / \mathrm{div}$; (a) without decoupling; (b) with decoupling.

The mentioned steady-state error of the torque-producing stator current control is presented in Figures 11a and 12a. The reference torque-producing stator current is $6 \mathrm{~A}$, but the real average value of the torque-producing stator current is $5.2 \mathrm{~A}$.

From Figures $11 \mathrm{~b}$ and $12 \mathrm{~b}$, it is evident that the reference and actual steady-state torque-producing stator currents are almost the same, both $6 \mathrm{~A}$. In this case, the control algorithm uses the decoupling block.

The presented experimental results demonstrate better dynamic performance of the control structure with the decoupling algorithm because of a higher torque-producing stator current during the transients of the rotor speed. In this case the acceleration time from 0 to $500 \mathrm{rpm}$ is shorter by about $20 \mathrm{~ms}$.

\section{Conclusions}

This paper presents that the steady-state error of the torque-producing stator current of the vector-controlled induction motor drive during the rotor speed transient-states can be eliminated using the presented correction decoupling algorithm. The fact was theoretically derived in (28) and confirmed by the simulation and experimental testing.

In the case of the vector control of the induction motor without the decoupling block, the mentioned current error depends on many drive parameters, see (26) and (25), for example, on the frequency converter gain, controller parameters, motor parameters, moment of inertia, magnetizing current etc. In the field weakening region of the drive, it is necessary to take into account the decreasing of the magnetizing current.

The experiment results confirmed the theoretical assumptions and the results from the simulation stage. If the decoupling algorithm is not used and the moment of inertia is $0.013 \mathrm{kgm}^{2}$, the steady-state torque-producing stator current during the drive acceleration is $4.98 \mathrm{~A}$ for the simulation and 5.2 A for the real laboratory model of the drive instead of the reference value equal to $6 \mathrm{~A}$. If the presented decoupling algorithm is used in the vector control structure, the steady-state current error is equal to zero for both the simulation and 
the experiment too. Of course, the presented decoupling block ensures independent control of the stator current space vector components.

This topic is important in the field of traction applications or robotics. In these cases, it is necessary to find methods to suppress the torque-producing stator current control error.

The above mentioned facts about the steady-state current control error caused by the back EMF changes can be applied with some modifications in other vector-controlled AC drives.

Author Contributions: Conceptualization, M.K., P.P. and D.P.; methodology, M.K. and P.P.; software, M.K. and M.S.; validation, M.K., M.S. and P.P.; formal analysis, M.K.; investigation, M.K., P.P. and D.P.; resources, M.K. and P.P.; writing-original draft preparation, M.K. and P.P.; writing-review and editing, P.P. and M.K.; visualization, M.K.; supervision, P.P. and D.P.; project administration, P.P.; funding acquisition, P.P. and M.K. All authors have read and agreed to the published version of the manuscript.

Funding: This research was funded by the Student Grant Competition of VSB-Technical University of Ostrava, grant number SP2022/48 and by the European Regional Development Fund-Operational Programme Research, Development and Education, grant number CZ.02.1.01/0.0/0.0/17_049/0008425 (Research Platform focused on Industry 4.0 and Robotics in Ostrava agglomeration).

Institutional Review Board Statement: Not applicable.

Informed Consent Statement: Not applicable.

Data Availability Statement: Not applicable.

Conflicts of Interest: The authors declare no conflict of interest.

\section{Nomenclature}

$F_{C C x} \quad x$-axis stator current controller transfer function

$F_{C C y} \quad y$-axis stator current controller transfer function

$F_{F C} \quad$ frequency converter transfer function

$F_{C S} \quad$ current sensor transfer function

$i_{m} \quad$ magnetizing current

$\mathbf{i}_{\mathrm{m}} \quad$ magnetizing current vector

$i_{S x}, i_{S y} \quad$ stator current space vector components expressed in $[x, y]$ rotating reference frame

$J_{t} \quad$ total moment of inertia

$L_{h} \quad$ magnetizing inductance

$L_{R}, L_{S} \quad$ rotor and stator inductance

$p \quad$ number of pole pairs

$R_{R}, R_{S} \quad$ rotor and stator resistance

$t_{E} \quad$ electromagnetic induction motor torque

$t_{L} \quad$ load torque

$T_{R}, T_{S} \quad$ rotor and stator time constant

$u_{S x}, u_{S y}$ stator voltage space vector components expressed in $[x, y]$ rotating reference frame

$\varepsilon \quad$ rotor position angle

$\gamma \quad$ orienting angle

$\delta \quad$ load angle

$\sigma \quad$ total leakage constant

$\Psi_{R} \quad$ rotor magnetic flux

$\Psi_{\mathrm{R}} \quad$ rotor magnetic flux vector

$\Omega_{1} \quad$ angular speed of stator current

$\Omega_{i m} \quad$ angular speed of magnetizing current

$\Omega_{m} \quad$ electrical rotor angular speed 


\section{References}

1. Bose, B.K. Global energy scenario and impact of power electronics in 21st century. IEEE Trans. Ind. Electron. 2013, 60, 2638-2651. [CrossRef]

2. Lisauskas, S.; Udris, D.; Uznys, D. Direct torque control of induction drive using fuzzy controller. Elektron. Elektrotechnika 2013, 19, 13-15. [CrossRef]

3. Aliskan, I.; Gulez, K.; Tuna, G.; Mumcu, T.V.; Altun, Y. Nonlinear speed controller supported by direct torque control algorithm and space vector modulation for induction motors in electrical vehicles. Elektron. Elektrotechnika 2013, 19, 41-46. [CrossRef]

4. Vas, P. Sensorless Vector and Direct Torque Control; Oxford University Press: New York, NY, USA, 1998.

5. Perdukova, D.; Palacky, P.; Fedor, P.; Bober, P.; Fedak, V. Dynamic identification of rotor magnetic flux, torque and rotor resistance of induction motor. IEEE Access 2020, 8, 142003-142015. [CrossRef]

6. Frivaldsky, M.; Dobrucky, B.; Prazenica, M.; Koscelnik, J. Multi-tank resonant topologies as key design factors for reliability improvement of power converter for power energy applications. Electr. Eng. 2015, 97, 287-302. [CrossRef]

7. Milicevic, D.; Katic, V.; Corba, Z.; Greconici, M. New space vector selection scheme for VSI supplied dual three-phase induction machine. Adv. Electr. Comput. Eng. 2013, 13, 59-64. [CrossRef]

8. Leonhard, W. Control of Electrical Drives, 2nd ed.; Springer: Berlin/Heidelberg, Germany, 1997.

9. Girovsky, P.; Timko, J.; Zilkova, J. Shaft sensor-less FOC control of an induction motor using neural estimators. Acta Polytechnica Hung. 2012, 9, 31-45.

10. Salmasi, F.R. A Self-healing induction motor drive with model free sensor tampering and sensor fault detection, isolation, and compensation. IEEE Trans. Ind. Electron. 2017, 64, 6105-6115. [CrossRef]

11. Merizalde, Y.; Hernández-Callejo, L.; Duque-Perez, O. State of the art and trends in the monitoring, detection and diagnosis of failures in electric induction motors. Energies 2017, 10, 1056. [CrossRef]

12. Liu, Y.; Stettenbenz, M.; Bazzi, A.M. Smooth fault-tolerant control of induction motor drives with sensor failures. IEEE Trans. Power Electron. 2019, 34, 3544-3552. [CrossRef]

13. Listwan, J.; Pienkowski, K. Comparative analysis of control methods with model reference adaptive system estimators of a seven-phase induction motor with encoder failure. Energies 2021, 14, 1147. [CrossRef]

14. Kuchar, M.; Palacky, P.; Simonik, P.; Strossa, J. Self-tuning observer for sensor fault-tolerant control of induction motor drive Energies 2021, 14, 2564. [CrossRef]

15. Tran, C.D.; Palacky, P.; Kuchar, M.; Brandstetter, P.; Dinh, B.H. Current and speed sensor fault diagnosis method applied to induction motor drive. IEEE Access 2021, 9, 38660-38672. [CrossRef]

16. Lorenz, R.D.; Lawson, D.B. Performance of feedforward current regulators for field oriented induction machine controllers. IEEE Trans. Ind. Applicat. 1987, IA-23, 142-150. [CrossRef]

17. Briz, F.; Degner, M.W.; Lorenz, R.D. Analysis and design of current regulators using complex vectors. IEEE Trans. Ind. Applicat. 2000, 36, 817-825. [CrossRef]

18. Harnefors, L.; Nee, H. Model-based current control of ac machines using the internal model control. IEEE Trans. Ind. Applicat. 1998, 34, 133-141. [CrossRef]

19. Jung, J.; Lim, S.; Nam, K. PI type decoupling control scheme for high speed operation of induction motors. In Proceedings of the 28th Annual IEEE Power Electronics Specialists Conference, St. Louis, MO, USA, 27 June 1997; pp. 1082-1085.

20. Jung, J.; Nam, K. A dynamic decoupling control scheme for high-speed operation of induction motors. IEEE Trans. Ind. Electron. 1999, 46, 100-110. [CrossRef]

21. Zhiling, L.; Hongping, J.; Guohai, L. Comparative Study on Vector Control and Differential Geometry Decoupling Control Method of Induction Motor. In Proceedings of the 2005 International Conference on Electrical Machines and Systems, Nanjing, China, 27-29 September 2005; pp. 1539-1543.

22. Sasakura, Y.; Kawakami, T.; Kawabata, Y.; Ejiogu, E.C.; Kawabata, T. Novel decoupled controller for vector controlled induction motor without rotor constant in the final formula. In Proceedings of the Power Conversion Conference, Osaka, Japan, 2-5 April 2002; pp. 384-389. 